\title{
A evolução da sexualidade masculina através do tratamento da ejaculação precoce sob a luz da terapia cognitivo-comportamental
}

\section{The evolution of the masculine sexuality through the treatment of the preco- cious ejaculation under the light of the behavior-cognitive therapy}

\author{
André Luís da Silva ${ }^{1}$ \\ Ana Claudia C. de Ornelas Maia ${ }^{2}$
}

Palavras-chaves:

Ejaculação

Precoce

Desenvolvimento

Sociossexuais
Artigo

Original

Original

Paper

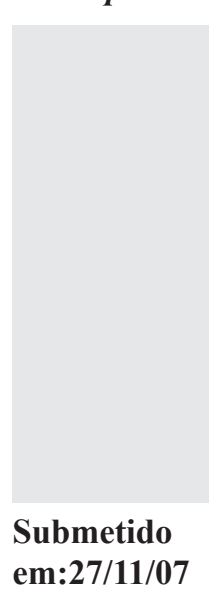

Revisado em:10/02/08

Precocious

Ejaculation

Development

Social and

Sexual
Aceito para
Publicação
em: 28/03/08 \begin{abstract}
cal case, the vision of the practical one in the sexual therapy, as the question of the masculine sexual disease is presented in this context, specifically the "precocious ejaculation". The proposal of a differentiated vision of treatment, with resultant practical experience of deep study of the subject in question.

Abstract

This work intends to raise next to behavior-cognitive therapy a theoretical and bibliographical study regarding the sexual description of the human
sexual development. It is observed that the sexuality comes presenting series of changes in the socials and sexuals papers masculine how much in such a way feminine, and with this, science goes following this constant process of the evolution human being. Through a demonstration of a clini-
\end{abstract}

\section{Introdução}

No decorrer da história, verificamos que tivemos significativa evolução no contexto da sexualidade, pois o tempo nos trouxe muitos esclarecimentos e quebraram-se muitos tabus e mitos que ocultavam o conhecimento sobre a sexualidade, pois o acesso a este conhecimento estava detido na mão de poucos, ditos como intelectuais ou representantes das correntes moralistas. A quebra destes tabus ajudou ao homem a conhecer melhor seu corpo, a melhor expressão dos sentimentos e da sexualidade; desta forma, a quebra de paradigma criou uma abertura muito promissora para o alívio dos distúrbios no mundo terapêutico. Neste trabalho buscamos levantar dados históricos da sexualidade para que, com isto, possamos entender como o homem encarou suas várias etapas da vida e a forma de lidar com o corpo e o sexo.

\footnotetext{
Psicólogo, aluno pós-graduando do curso de terapia cognitivo-comportamental nas instituições e na clínica na UNIFOA

${ }_{2}^{2}$ Psicóloga, especialista em terapia cognitivo-comportamental, mestre em sexologia clínica, coordenadora do curso de pós-graduação de terapia cognitivo-comportamental nas instituições e na clínica na UNIFOA e professora do curso de psicologia da UNESA.
} 
As disfunções sexuais se estendem por vários segmentos; aqui nos detemos na disfunção sexual masculina, especificamente na ejaculação precoce e através da abordagem na literária e no tratamento na visão da terapia cognitiva comportamental. Desta forma lançamos mão a um tratamento que leva o paciente a compreender as razões que o mantém nesta problemática, buscando mudar suas crenças e levá-lo a uma solução prática na forma de sanar esta questão que ainda é pertinente no quadro da realidade sexual masculina.

Esta exposição tem como objetivo agregar a literatura e mais um trabalho de intervenção clínica a respeito da ejaculação precoce, com a oportunidade de apresentar alternativas práticas, sem lançar mão dos dados psicopatológicos e fisiológicos do paciente. Assim sendo, cria-se a possibilidade de fazer com que o paciente que sofre deste distúrbio possa ter uma melhor qualidade na relação sexual; auxiliando a resolver as ações pertinentes, destrutíveis que o alimenta a manter-se nesta situação; visando sempre trazer o esclarecimento não só ao paciente, mas à companheira, buscando criar uma parceria e compromisso para que o tratamento possa a ter um objetivo desejado.

Existem na sociedade necessidades urgentes para o equilíbrio do bem comum, desta forma, encaramos que o distúrbio desta natureza que até hoje é muito pouco divulgado no convívio social, nas literaturas do ramo e até mesmo nos meio de comunicação podendo trazer um benefício importante para quem convive com a problemática da ejaculação precoce; pois quem convive com este distúrbio carrega consigo um enorme desconforto no campo da sexualidade. Assim, desejamos que esta obra possa contribuir no alívio desta disfunção, sendo também um material de pesquisa aos profissionais da saúde, como também ao público em geral.

\section{Histórico da Sexualidade}

Falar da sexualidade é mergulhar nos meandro da história, é compreender que desde a pré-história, quando o homem buscou conviver em grupo, houve a necessidade de regras para o convívio social. Nesta época a vida era muito precária, a norma básica era a sobrevivência, sendo o sexo inserido no meio grupal de uma forma não tanto pacífica. No decorrer do tempo, o homem deixa de ser nômade e procura se instalar em lugares específicos, plantando, criando animais, zelando pelo seu espaço. Neste momento sexo deixa de ser biológico e passa a ser cultural, respeitando suas normas, suas crenças e seus valores.

$\mathrm{Na}$ História antiga, especificamente na Grécia, onde a beleza e o aspecto físico eram cultuados em nome do poder, o homem acreditava que o corpo abrigava um espírito nobre onde Eros simbolizava o Deus do Amor, inspirando a natureza e a humanidade. Na referida época, só os homens livres eram considerados cidadãos e as mulheres, crianças, escravos e estrangeiros encontravam-se à margem da sociedade, vivendo assim em uma postura de inferioridade. $\mathrm{O}$ grego aceitava o homossexualismo e o bissexualismo, mas discriminava o homem efeminado, nesta sociedade; a virgindade não era valorizada por razões morais. O casamento era monogâmico e, na teoria, a mulher poderia pedir o divórcio em caso de provocação extrema, mas, certamente, a infidelidade do marido não estava incluída neste tipo de provocação.

Em Roma, diferentemente da Grécia, o homem valorizava a virgindade, pois acreditava que caso se casasse com uma mulher que não fosse virgem provavelmente ela seria infiel ao marido. Contudo, o papel da mulher ainda seria do lar, não possuindo nenhuma atribuição social. $\mathrm{O}$ homossexualismo e bissexualismo não eram problemas para os romanos, embora o homossexualismo não tivesse o refinamento que o caracterizava na Grécia. A prostituição era aceita e os bordéis eram muito comuns nas cidades romanas; os homens poderiam ser infiéis, mas as mulheres se os fossem, seriam mortas pelos maridos, licitamente em nome de sua honra.

Os hebreus apresentavam um diferencial muito importante diante dos povos da antiguidade, pois tinham "o Decálogo" como código moral religioso e eram monoteístas. Sua sexualidade era vista com naturalidade, sua crença sobre a sexualidade era voltada para a procriação. A mulher sofria alguns 
preconceitos, um deles o da menstruação, que atribuía um estado de impureza da mulher. No período da menstruação as mesmas eram proibidas a ter relações sexuais assim como a qualquer tipo de toque.

Para Araújo (2002, pág.20),

"Os judeus condenavam a prostituição e a infidelidade, que eram punidas com o apedrejamento. Condenavam também qualquer tipo de relação sexual em que o sêmen não fosse depositado na vagina (na relação anal ou no coito interrompido, por exemplo). A mulher era importante como agente na transmissão da cultura, pois por intermédio dela as crianças aprendiam tudo o que deveriam saber referente a seu povo".

$\mathrm{Na}$ Antiguidade o cristianismo se implantou num período em que Roma já havia incorporado os valores gregos relacionados a harmonia e beleza, no plano da política e da filosofia. Nesta fase o cristianismo caracterizou-se, no início, por intensa repressão à sexualidade e extrema valorização da virgindade e da castidade. Para o grego não havia a noção do pecado e o que ele valorizava era a harmonia do ser. O desenvolvimento das virtudes tinha o objetivo de tornar o homem senhor dos desejos e não escravo das paixões; o sentido da virtude não era religioso e sim existencial.

Santo Agostinho, intelectual da época, deixou imensa obra de teologia moral em que, por razões particulares, colocou o sexo como fonte de pecado. Era adepto ao controle da natalidade, pois acreditava que cada criança que nascia aumentava as trevas e somente por meio da ascese pessoal conseguiria purificarse para alcançar a vitória da luz. Contrapôs a virtude ao vício e, excetuando o sexo sem prazer para a procriação, via a prática sexual como pecado; defendia que não devia haver paixão entre os cônjuges, pois assim ficaria mais fácil abdicar do sexo em função da família.

$\mathrm{Na}$ Idade Média, que abrange o período da queda do Império Romano, no ano 476, até a queda de Constantinopla, em 1453, época em que a moral e religião ainda estavam juntas, a igreja intervinha no campo religioso, acima de tudo no âmbito social. A questão sexual se insere, dessa forma, nos meandros da religião católica. A repressão à sexualidade era muito grande e o sexo só era aceito dentro do casamento e com a finalidade de procriação, além de várias restrições impostas pela igreja. A partir do século VIII, surgiu o amor cortesão que começou a transformar as atitudes em relação ao amor e ao sexo, pois envolviam novos ideais filosóficos e sentimentos sobre a relação homem e mulher. Buscava-se o amor puro, que excluía totalmente o amor sexual. Nessa época, foi difundida a crença de que o homem que amasse ardentemente sua mulher seria adúltero.

No início do século XIV, a sexualidade sofreu repressão novamente devido ao medo das bruxarias, pois relacionavam as parteiras, que faziam simpatias e porções para mulheres não engravidarem ou para abordarem. Este fato foi acompanhado da temente caça as bruxas. No referido período surgiram diversas epidemias, sendo a peste bubônica a que obteve maior repercussão, dizimando quase metade da população da Europa. A igreja passou a ser questionada, seu poder foi alvo de controvérsia, sendo aberto a partir disso um novo campo para o aparecimento de numerosas seitas heréticas. Numa época em que as mulheres eram acusadas de enfeitiçar os homens, é evidente o conteúdo sexual de atos tachados de feitiçaria. Sem muito conhecimento do psiquismo humano, muitas mulheres e doentes mentais foram perseguidos, torturados e condenados à morte.

O Renascimento foi um período de transição entre a Idade Média e a Idade Moderna, o artista foi o grande herói do Renascimento. Leonardo Da Vinci, Michelangelo, Rafael e Boticelli são apenas alguns nomes da grande quantidade de talentos que se celebrizaram, dando expressão visual ao ideal e espírito da época. É um momento em que Roma vivia novamente uma fase de extrema liberdade sexual; havia, inclusive, bordéis que funcionavam com a autorização da Igreja.

Nesta fase houve o surgimento da Sífilis, que se tornou um dos maiores flagelos da humanidade; as lesões desta doença 
eram percebidas com muita ansiedade pela população. Considerada um castigo de Deus para punir a promiscuidade, a doença teve como conseqüência a restrição à prostituição.

Neste momento a Igreja caracterizouse por uma fase de muita ambivalência, mantendo-se firme na decisão referente ao celibato dos padres, embora muitos deles mantivessem relações sexuais e tivessem filhos às escondidas.

\section{Conforme Araújo (2002 pág. 25),}

"O padre Martinho Lutero insurgiuse contra tudo isso e liderou a reforma Protestante, separando-se da Igreja Católica. Ele não aceitava as doutrinas referentes a indissolubilidade do casamento, ao celibato dos padres e à virgindade de Maria. Ele reconhecia o impulso sexual e propunha que aqueles que não pudessem viver em castidade deveriam casar-se, sem prejuízo dos deveres religiosos".

Esta reforma fez com que a Igreja Católica tomasse outro ponto de vista em relação á moral sexual; uma delas foi a aceitação do controle da natalidade. Porém somente os meios naturais poderiam ser praticados, ou seja, a continência nos dias férteis da mulher.

Com o aparecimento da burguesia, a partir do século XVI, a sociedade passou por grandes transformações; os grandes comerciantes enriqueceram e se transformaram numa nova classe social. Este processo de modernização provocou maior interiorização das emoções e o sexo passou ao domínio privado da existência. As casas ganharam quartos, camas fixas, salas de refeição e de estar; tais mudanças geraram um marco na manifestação da intimidade e das privações da família.

Uma das características da época é que os educadores moralistas não eram necessariamente religiosos (padres, freiras ou pastores); criticavam a sociedade e educavam as crianças num ambiente de recato e pudor. Os jovens foram educados de forma a dirigir sua atenção para os estudos, como meio de canalizar a energia sexual reprimida. Nos colégios eram evitadas todas as situações que propiciassem contato de natureza sexual entre os jovens. Combatia-se a masturbação. Toda essa repressão sexual provocou uma sexualização de estímulos que até então eram neutros.

No final do século, Freud introduziu o conceito de inconsciente, que explicava o mecanismo de recalcamento e repressão. Passou-se então a entender como o sexo pode ser reprimido e manifestar-se em situações aparentemente não sexuais.

O Século XX foi marcado por inúmeras transformações científicas e tecnológicas que determinaram a difusão de novas idéias, paralelamente, o comportamento sexual se modificou, tornando-se mais aberto e liberto de preconceitos. A mulher inicia a reivindicação de um lugar para si na sociedade, buscando sua liberdade profissional e financeira, pois não admitia mais ser a sombra do marido.

O homem começa a aceitar a dividir a liderança com a classe feminina, assim como quebrar os paradigmas dos preconceitos que o distanciava das mulheres. Os movimentos feministas questionavam a situação da mulher, a virgindade, o aborto e o casamento; o movimento Gay assumiu características políticas, sendo importante para estudos sobre a sexualidade, pois foi a primeira vez que os homossexuais enfrentaram preconceitos e assumiram uma postura política. Com o surgimento da AIDS na década de 80, o mundo ficou chocado com a gravidade deste mal que assombrou a humanidade. Diante deste fato, o homem teve que tomar uma nova postura na educação, não apenas enfocando a procriação, mas principalmente, abordando o sexo como um dos constituintes da vida do ser humano.

Após este breve levantamento histórico da sexualidade, é possível dar continuidade a este estudo, abordando um dos traços da disfunção sexual masculina, especificamente "a ejaculação precoce".

\section{Disfunções Sexuais, Anatomia e Fisiologia dos Orgãos Genitais Masculino}


As disfunções sexuais provêm de um fundamento lógico muito diferente das relações anteriores entre a criança e os pais. Os problemas sexuais são adquiridos (em qualquer estágio de vida) de maneira que são explicados pela teoria do aprendizado, podendo, portanto, ser modificados mediante a utilização de métodos de tratamento baseados nos princípios do aprendizado. Dessa forma, consideramos que existem disfunções sexuais primárias e secundárias. As primárias são aquelas que nunca permitiram que o indivíduo tivesse um bem estar nas relações sexuais, nem mesmo sozinho, na masturbação. As secundárias são aquelas em que algumas vezes o indivíduo já sentiu prazer e deixou de sentilo.

Podemos dizer que um casal sofre de uma disfunção sexual quando um dos pares não completa as fases do intercurso sexual; sejam elas, desejo, excitação, platô, orgasmo ou resolução. Essas fases se diferenciam quanto ao papel masculino e feminino. Pois a mulher, nas fases de platô e orgasmo, pode permanecer mais tempo do que o homem, ou seja, o homem passa rapidamente da fase do orgasmo para resolução da satisfação sexual. Isso se deve à explicação da mulher ser multiorgásmica.

No contexto da sexualidade, não há como deixar de relatar as alterações da anatomia e fisiologia em ambos os sexos, no intuito de preparar os parceiros para o ato sexual. No homem, a alteração dos órgãos sexuais é bem visível, pois no processo de excitação o pênis sofre uma dilatação nos vasos sanguíneos internamente, em conseqüência aos estímulos sexuais.

Segundo Kaplan (apud, Masters e Johnson, pg. 22, 2001), a fisiologia sexual masculina divide-se em quatro estágios sucessivos: excitação, platô, orgasmo e resolução. A excitação é representada no homem pelo movimento súbito de sensações eróticas e conseqüentemente a ereção do pênis; em conseqüência, o escroto se dilata, a bolsa escrotal fica mais lisa e maior e os testículos ficam mais elevados. O platô é representado pelo ápice da excitação, que acontece logo antes do orgasmo; neste momento o pênis está dilatado, o corpo cavernoso e esponjoso está cheio de sangue até o seu limite máximo, com a ereção firme e seu tamanho chega a seu máximo e os testículos super irrigados de sangue cresce consistentemente, as vísceras seminais se contraem e depositam a ejaculação no canal peniano.

O orgasmo representa o prazer mais intenso das sensações sexuais no homem; neste momento as vísceras reprodutoras internas, a próstata e o canal deferente fisiologicamente ereto e volumoso, ritmado por várias convulsões vibratórias, lançam o sêmen em várias ejaculações. A resolução é representada pelo ciclo final da resposta sexual; neste momento a fisiologia do pênis que estava sem seu ápice volta gradativamente ao seu estado normal, os estímulos somáticos que estimulam os órgãos sexuais diminuem rapidamente, os testículos que estavam com seu volume alterado também volta para o seu tamanho habitual. Em estado de repouso, o pênis é flácido devido os corpos cavernosos estarem com pouco sangue e o corpo esponjoso e os testículos em estado normal ficam para baixo.

\section{Definição e Conceitos da Ejaculaçao Precoce}

Dentre as disfunções sexuais masculinas, a ejaculação precoce, ou ejaculação prematura, é um dos assuntos relativos à esfera sexual que mais preocupa os homens. No interior da volumosa literatura sobre sexo e sexualidade há muito pouco sobre a ejaculação precoce e uma enorme carência de métodos e profissionais voltados para o esclarecimento deste assunto.

Conceitua-se essa disfunção
por ejaculação precoce porque ocorre a
incapacidade de reter voluntariamente a
ejaculação. Somente indica-se o tratamento
para esse diagnóstico quando se comprova
junto à parceira que o tempo de reter a
ejaculação é realmente muito curto, ou quando
nem ainda sequer ocorra a penetração.

Masters e Johnson (1970), demonstraram que um forte componente de aprendizagem estaria intimamente ligado à ejaculação precoce e que os homens se condicionariam a uma fácil e rápida ejaculação, estabelecendo esse padrão de

(1)

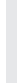

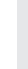


comportamento sexual por toda a vida. A ansiedade também é apontada como uma grande causadora da ejaculação precoce, portanto o condicionamento não pode ser a única hipótese para a queixa.

A ejaculação precoce refere-se a ejaculaçãocomumaestimulaçãosexualmínima, antes, no momento ou pouco tempo depois da penetração e "antes do que a pessoa desejaria".

Este último ponto pode ser difícil de diagnosticar porque não está claro o que deveria ser considerado como uma duração "normal" do contato sexual antes do orgasmo. É possível que alguns homens e mulheres tenham expectativas pouco realistas com respeito ao tempo que teve transcorrer antes do orgasmo, e os clínicos podem não estar de acordo sobre a definição precisa de "precoce". Entretanto, os casos mais claros incluem habitualmente ejaculação antes da introdução (quando se deseja o coito) ou imediatamente depois da penetração. Outros autores adotam, em sua prática clínica, o conceito de ejaculação precoce como sendo a incapacidade de reter voluntariamente a ejaculação (Bestane, 2003). Sendo assim, todo aquele que ejacula antes do desejado, por não inibir voluntariamente a ejaculação, padeceria de ejaculação precoce. Esse conceito atual de ejaculação precoce deve ser apreciado com reservas, tendo em vista que o homem de hoje se encontra pressionado cada vez mais por um desempenho maior em detrimento de seu prazer.

Algumas variações devem ser consideradas como critério válido para o ejaculador precoce; como exemplo a variação de permanência dentro da vagina, isto é, a quantidade de impulso que pode tolerar antes do orgasmo. Há casos que a ejaculação acontece a poucos minutos de carícia antes do ato sexual, ou mesmo só vendo a parceira de despindo.

Segundo Kaplan (2001) muitos ejaculadores prematuros ejacularão justamente antes ou imediatamente depois que introduzem na vagina, mas outros são capazes de alguns impulsos antes de atingir o orgasmo; podese dizer que existe prematuridade quando o orgasmo ocorre como um reflexo, isto é, quando está fora do controle voluntário do homem, uma vez atingido um nível intenso de excitação sexual. Inversamente, pode-se dizer que o controle ejaculatório está estabelecido quando o homem pode tolerar os elevados níveis de excitação que caracterizam o estágio do platô do ciclo da resposta sexual sem ejacular como um reflexo.

\section{Fatores Predisponentes e Mantenedores da Ejaculação Precoce}

Uma das maiores queixas do ejaculador precoce e da sua companheira é a rapidez do orgasmo; mais muitas outras considerações devem de ser colocadas diante este evento, como o nível de estresses que o ejaculador vai para a relação sexual, fazendo o mesmo aumentar ou diminuir a percepção da sensação erótica, uma vez que ele fica intensamente excitado. No momento do coito o ejaculador precoce tem a sensação que seu órgão sexual (pênis) fica muito sensível, e o responsabiliza de seu orgasmo prematuro, e muitas das vezes não consegue enxergar que este mecanismo é apenas um efeito e não a causa de seu problema.

Muitas vezesa formaqueoadolescente inicia sua vida sexual pode contribuir para que o torne um ejaculador precoce; pois muito tem sua primeira relação, em transa rápida dentro de um carro, em prostíbulos ou saídas com prostitutas, no qual estas profissionais na ânsia de conseguirem outros clientes; tem o seu tempo cronometrado, não tem paciência com os adolescentes que muitas vezes tem o orgasmo prematuro e não entende por falta de conhecimento que este comportamento é normal nas primeiras relações. Mais por desconhecimento de causas muitos deles levam para sua vida a incapacidade de ter uma ejaculação sem ser prematura. Nisto começa todo um processo, onde a "ansiedade do bom empenho na relação sexual" toda conta da sua vida, fazendo com que toda vez que vai para uma relação, leva a ânsia de se ejacular rápido.

Socialmente o homem é muito cobrado no bom desempenho sexual, para a sua satisfação e o bom desempenho com a parceira; pois o bom amante é responsável na boa condução da relação sexual, pois mesmo muito excitado, deve saber conduzir os jogos 
sexuais, as carícias, os afagos até conduzir sua parceira ao clímax orgástico. Vários casamentos têm um final infeliz em função desta disfunção masculina, pois o homem não sabendo lidar com este problema, deixa a parceira à mercê de uma boa satisfação sexual e muitas vezes culpa a parceira pelo seu fracasso ejaculatório. Algumas mulheres revidam esta acusação e outras se sentem deprimida, se achando fria e não preparada para criar um ambiente tranqüilo para uma boa performance na relação de ambos.

O ejaculador prematuro leva consigo muita ansiedade e uma enorme parcela de culpa por não ter um bom desempenho sexual e um enorme desapontamento, pois seu prazer sexual é incompleto e muito rápido. Esta situação o deixa numa situação de muita vergonha e infelicidade, levando a conseqüência amarga, pois o ejaculador prematuro passa evitar os contatos sexuais no medo de frustrar na relação. Os efeitos psicológicos de angústia e de incapacidade não deixam outra saída ao ejaculador precoce a não ser buscar ajuda, de outra forma os efeitos serão altamente destrutivo para sua relação conjugal.

\section{Tratamento da Ejaculação Precoce na Terapia Cognitivo-Comportamental}

Existem vários tratamentos para o retardamento da ejaculação precoce como, por exemplo: a masturbação antes do coito, banho de chuveiro frio, uso de álcool e sedativos, repetitivas práticas sexuais com a parceira até o orgasmo, o uso de preservativo ou a aplicação de analgésico no pênis para diminuir a sensibilidade, a prática de exercícios mentais para desviar atenção no ato sexual focalizada em experiência desagradável. Todos estes métodos de uma forma ou outra auxiliam como mecanismo para retardar o início da excitação aguda, mas não melhoram o controle, desde que seja atingida intensa excitação erótica. No tratamento farmacológico, uma das drogas utilizada no mercado é o "Meleril", que causa o orgasmo seco, devido à emissão em sentido inverso da ejaculação na bexiga em lugar de na uretra; alguns médicos indicam antidepressivos para o controle ejaculatório.

No tratamento para as disfunções sexuais devem-se englobar fatores afetivos, cognitivos e comportamentais. Idealmente o tratamento transcorre com eficiência se for feito com o casal, porém hoje em dia, caso o parceiro ou a parceira não quiser acompanhar o atendimento terapêutico, pode-se encaminhar o tratamento de forma individual, porém isso pode acarretar em aumentar o tempo de resolução da situação problemática.

Kaplan (apud Pomeroy, pg. 286, 2001) acredita que a ansiedade é o problema básico na ejaculação prematura. De acordo com esta formulação, o homem experimenta a ansiedade exatamente ao atingir os altos níveis de excitação erótica, é esta ansiedade que dispara o orgasmo involuntário. Outras correntes psicológicas voltam para o tratamento da ejaculação precoce; a psicanálise objetiva desvendar os conflitos inconscientes que se presume ser a raiz do problema do paciente, mas nas melhores intenções, só produz resultados discutíveis e como a ejaculação precoce precisa de uma prova prática, no sentido de comprovar a melhora, esta teoria precisa de uma revisão para ter uma resposta positiva diante desta disfunção. A terapia behaviorista apenas diminui a ansiedade associada à relação sexual.

É muito comum que após a investigação do caso o terapeuta perceba que a disfunção sexual pode ter sido desencadeada por falta de informação e/ou por tabus morais. Nesse caso, faz-se necessário que o terapeuta realize uma reeducação sexual na terapia.

Os principais objetivos na terapia sexual são:

A) Definir a natureza da disfunção sexual e quais são as mudanças desejadas;

B) Obter informações que permitam ao terapeuta propor uma formulação em termos de fatores predisposicionais, precipitantes e mantenedores;

C) Com base nesta formulação, definir qual o melhor tipo de intervenção terapêutica;

D) Iniciar o processo terapêutico;

E) Avaliar o processo e introduzir eventuais mudanças no planejamento, se necessário;

F) Tomar medidas para a prevenção de recaídas.

No caso das disfunções sexuais, para o tratamento faz-se necessário à proibição da penetração durante o tratamento até segunda 
ordem, pois a penetração é o que causa a maior ansiedade no que consiste ao desempenho sexual. Programa-se dessa forma, encontros do casal para namoro, massagens com cremes ou óleos sem cheiro (o creme da marca Nívea é ótimo para esse tipo de massagem), primeiro no corpo todo e com roupas; depois tirando cada peça de roupa, conhecendo o seu próprio corpo e do outro, com a finalidade de reconhecerem partes sensíveis e agradáveis de serem acariciadas. E assim, os toques, os carinhos, as comunicações vão prosseguindo gradativamente com o objetivo de favorecer as sensações de prazer e bem estar. Todo lugar é um local de encontro do casal, é importante que então façam desses encontros sempre em clima agradável e de sedução.

Para ser tratada a ejaculação precoce, primeiro o homem deve treinar a masturbação sozinho e parar antes de ejacular, programando um tempo maior a cada exercício de masturbação, cada vez mais os estímulos podem ser introduzidos aos poucos (por exemplo: a fantasia, o óleo na mão, as revistas ou filmes, a parceira, etc).

Conforme Kaplan (2001), as técnicas mais eficientes desenvolvidas até agora são as modeladas no método "Semans", que emprega repetida e prolongada estimulação do pênis pela parceira e interrompe a um sinal do paciente, exatamente antes de disparado o reflexo orgâsmico. Não obstante a eficiência da técnica de Semens, a razão em que ele se baseou esta suspeita a discussão. A característica essencial da prematuridade não parece ser a "rapidez" do reflexo ejaculatório, como declarou Semans, mais sim a ausência de controle voluntário sobre o reflexo é fator central desta condição.

Até hoje não é esclarecida a razão de que o ejaculador precoce não aprendeu a ter continência voluntária; o máximo que se investiga é o porque ele não consegue ter o controle ejaculatório, porque não recebeu, ou melhor, não permitiu receber o feedback sensorial necessário para trazer sob controle qualquer função reflexa. Aprender a ter continência ejaculatória é análogo ao processo de obter controle sobre outras funções biológicas que envolvem descarga reflexa. Por exemplo, uma criança está com a bexiga cheia, ela esvazia automaticamente, pois este controle ela só vai ter quando passa a ter a percepção de sentir quando é que a bexiga está cheia, daí ela passa a ter um controle voluntário sobre o órgão de descarga, seguindo esta linha, o ejaculador precoce não percebe claramente as sensações premonitórias do orgasmo; ou seja; são privados do poder regulador das influências dos nervos superiores, como resultado, a ejaculação ocorre automaticamente. O objetivo do tratamento da ejaculação precoce é induzir o paciente a focalizar repetitivamente a atenção nos níveis prolongados e intensos de excitação; na expectativa de que tal experiência capacita a obter controle ejaculatório. No intuito de ensinar ao ejaculador precoce a perceber as sensações pré-orgásmicas intensamente eróticos e a não deixar distrair por processo de envolvimento sexual com a mulher.

Na condição terapêutica, inicialmente efetua-se uma avaliação buscando conhecer o histórico detalhado do paciente, que apresenta seu sintoma e de sua disfunção; é orientado ao casal que cabe exclusivamente a eles a responsabilidade do sucesso do tratamento, expondo ao casal um quadro realista do que pode ser esperado.

Busca verificar no paciente e na esposa se existe alguma anomalia física nos órgãos genitais oriunda de doença ou mesmo congênita; em dúvida, o paciente é orientado a fazer uma avaliação médica, para que se possa dar continuidade ao tratamento. Serão discutidos durante a entrevista inicial outros fatores que contribuem para o sucesso do tratamento, como a dedicação, a franqueza, a respeito de sexualidade, a quebra dos mitos e as crenças errôneas a respeito do comportamento sexuais. Concluindo a primeira parte, o casal é orientado como dever de casa a realizar estimulação sexual mútua, isto é, apenas até o ponto de levar o marido à ereção.

O paciente deve deita-se de costa, enquanto sua esposa manipula seu pênis manualmente (ou oralmente se preferir), recomenda-se a ele focalizar a atenção exclusivamente nas sensações eróticas oriunda de seu pênis, enquanto o mesmo estiver sendo manipulado. Ele é orientado para não deter sua atenção à sua mulher porque a ansiedade e conflitos que surgem da preocupação com a parceira e das suas reações constituem distrações da experiência sexual. Além disto 
deve ater o pensamento às sensações eróticas; é orientado à mulher que pare de estimular o parceiro logo que sentir sensação orgástica premonitória. Ele notará que a sensação para dentro de alguns minutos. Antes de perder a ereção, é reiniciado a estimulação a um sinal; e de novo interrompido exatamente antes do orgasmo. O casal deve repetir este processo por três vezes e na quarta vez, ele ejacula. Em nenhum momento o paciente deve tentar exercer controle consciente sobre o orgasmo, exceto para pedir a mulher na hora de parar a estimulação.

Todo este trabalho deve ser realizado com muita cumplicidade, envolvido de afeto e carinho. Após este passo, devemos colocar uma forte ênfase na necessidade do paciente em focar a atenção nas sensações eróticas. Com este intuito, o paciente é orientado após a segunda experiência em casa a colocar sua mão sobre a da mulher e experimentar as sensações produzidas pela variação de velocidade, pressão e variações locais. Se todos estes passos forem bem sucedidos, o procedimento parte para uma nova etapa; desta vez o pênis deve ser lubrificado e continuar sendo manipulado, tendo a sensação do recinto interior de uma vagina lubrificada. Após uns seis exercícios, ejaculando sempre após a quarta ereção, espontaneamente o paciente relata que teve alguma melhora no controle orgásmico.

Neste ponto o coito é sugerido, a mulher deve manter na posição superior, ele deve introduzir o pênis de preferência bem lubrificado com vaselina ou outro creme lubrificante para inibir sua sensibilidade; deve manter sua mão no quadril da mulher, ela abaixa-se até o falo ereto e espera pelo sinal dele para começar a estimulação. O paciente fica deitado em silêncio conduzindo com as mãos os impulsos pélvicos da mulher; os movimentos devem ser interrompidos quando atingir o nível de sensação pré-orgásmica. Neste momento, o pênis deve permanecer imóvel até a sensação diminuir, então, o impulso é recomeçado.

Na quarta sessão, o paciente deixa que ocorra o orgasmo no coito, tendo um melhor controle por este meio; o homem busca novas experiências de coito com a mulher na posição de lado, mas mantendo ativamente os impulsos (mantendo o pare e continue), ele deve, sempre focalizar nas suas sensações sexuais durante os contatos de amor. Durante este período do tratamento o terapeuta deixa a mulher ciente que a principal tarefa terapêutica é fazer com que o homem se concentre na sua estimulação erótica, sem distração. Ela pode neste momento chegar ao orgasmo por outros meios; um deles é através da manipulação no clitóris, antes ou depois que ele tenha ejaculado, até que o parceiro tome o ritmo de controle ejaculatório. Durante o tratamento, o terapeuta fica aberto a todas as dúvidas para que o paciente tenha êxito neste tratamento.

O fundamental na Terapia Sexual é o conhecimento do próprio corpo; esclarecimentos sobre os efeitos da ansiedade na resposta sexual humana; aprendizagem de como se comunicar com o outro; práticas de relaxamento; valorização das fantasias; desfocalização dos genitais como centro de prazer.

\section{Conclusão}

Ao concluir este trabalho entendemos que a ejaculação precoce, dentro do quadro da disfunção sexual masculina, tem tratamento: basta o paciente assumir suas dificuldades e, a partir da revisão dos conceitos, crenças e dedicação que a proposta da terapia cognitiva comportamental apresenta, com certeza ficará livre do desconforto desta disfunção. Desta forma, ressaltamos que a contribuição desta obra aumenta a auto-estima do paciente livrando-o da ansiedade que o alimenta neste processo em busca do êxito na sua performance sexual. Por outro lado, poderemos contribuir para um tratamento buscando o alívio desta desordem sexual, que traz muito desconforto na relação conjugal, levando ao paciente e sua parceira a muita incerteza e insegurança na área sexual.

Concluímos também que as mudanças ao longo do tempo contribuíram muito no desenvolvimento do conceito da sexualidade. Hoje em dia, a sexualidade não é mais vista como algo sujo ou vulgar. De acordo com os estudos bibliográficos apresentados, percebemos que através de um conhecimento amplo do próprio corpo humano e a melhora na comunicação do casal, ocorre um fator atenuante na ansiedade de desempenho sexual.

\section{(⿸丆口}


A evolução sexual começa a abordar então mudanças nos papéis tanto do homem quanto na mulher na sociedade e também, porque não dizer, na sexualidade. De fato, as mudanças só contribuíram no desempenho da sexualidade humana; hoje em dia, a criação dos filhos é mais esclarecedora no que se diz respeito à educação sexual e existem as conversas entre pais e filhos, entre professores e alunos, com objetivos de um melhor entendimento e aproveitamento das relações sexuais, bem como, na proposta de prevenção de doenças sexualmente transmissíveis, gravidezes prematuras e porque não mencionar de uma futura disfunção sexual. Assim sendo, podemos afirmar que este trabalho é ousado por trazer uma abordagem inovadora na forma de tratar a prematuridade ejaculatória, pois não menospreza qualquer forma de tratamento que é direcionada a esta problemática. Busca aplicar uma terapia que objetiva melhor compreender os mecanismos que envolvem esta disfunção, e numa atitude aplicativa, procura tratar esta desordem de forma a contribuir positivamente no alívio dos pacientes que sofrem com esta disfunção.

\section{Referências}

ABDO, Carmita, Depressão e Sexualidade. São Paulo, Lemos Editorial, 2005.

ARAUJO, M. L. in TANAHILL, F. A história da sexualidade. Vozes, Petrópolis, 2002.

BESTANE, W.J, MEIRA, A.R, KRAUSER, M.R. Alguns aspectos da sexualidade e a prescrição de medicação para o tratamento da gonorréia em farmácias de Santos. Rev Ass Med Bras 2003;26:2-3.

CARVALHO, Antônio.in RANGÉ, B. Psicoterapias cognitivo-comportamentais: um diálogo com a psiquiatria. Porto Alegre, ARTMED, 2001

CHERMAN, Sheiva. Sexo x Afeto. São Paulo, Editora Saraiva, 1996.

FALCONE, Eliane in RANGÉ, B. Psicoterapias Cognitivo-Comportamentais: um diálogo com a psiquiatria. Porto Alegre, ARTMED, 2001

KAPLAN, Heln Singer. A Nova Terapia do Sexo. São Paulo, Editora Nova Fronteira, 2001.

KNAPP, Paulo. Terapia CognitivoComportamental na Prática Psiquiátrica. Porto Alegre, Artmed, 2004.

MASTERS \& JOHNSON, Inadequação sexual humana. São Paulo, EPU, 1970.

SILVA, Araguari Chalar. Terapia do Sexo e Dinâmica do Casal. São Paulo, Espaço e Tempo, 2002.

Informações bibliográficas:

Conforme a NBR 6023:2002 da Associação Brasileira de Normas Técnicas (ABNT), este texto científico publicado em periódico eletrônico deve ser citado da seguinte forma:

SILVA, A. L.; MAIA, A. C. C. O.. A evolução da sexualidade masculina através do tratamento da ejaculação precoce sob a luz da terapia cognitivo-comportamental. Cadernos UniFOA, Volta Redonda, ano 3, Edição Especial, maio. 2008. Disponível em: <http://www.unifoa.edu.br/pesquisa/ caderno/especiais/pos-graduacao/01/87.pdf> 